http://jmscr.igmpublication.org/home/ ISSN (e)-2347-176x ISSN (p) 2455-0450 crossref DOI: https://dx.doi.org/10.18535/jmscr/v9i12.05

\title{
A Study of Assessment on Psychological Well-being among Spouses of Bipolar Disorder Patients
}

Authors

\section{Dr Sathish Sankar PR, ${ }^{1}$ Dr Gandhi Babu $R,{ }^{2}$ Dr Aravindh $M^{3}$}

${ }^{1}$ Postgraduate, Department of Psychiatry, Rajah Muthiah Medical College and Hospital, Annamalai University, Chidambaram, Tamilnadu

${ }^{2}$ Professor and Head, Department of Psychiatry, Rajah Muthiah Medical College and Hospital, Annamalai University, Chidambaram, Tamilnadu

${ }^{3}$ Postgraduate, Department of Psychiatry, Rajah Muthiah Medical College and Hospital, Annamalai University, Chidambaram, Tamilnadu

Abstract
Background: Bipolar affective disorder [BPAD] is characterised by recurrent episodes of hypomania,
mania, euthymia and depression or a mixed state. This disabling illness causes significant degree of
burden on the caregivers which further affect their psychological wellbeing. The aim of this descriptive
study is to assess the psychological wellbeing among spouses of patients with bipolar affective disorder in
a Psychiatry Outpatient Department at Rajah Muthiah Medical College and Hospital, Chidambaram.
Results: Male spouses have significantly higher scores in psychological well-being. The mean PGWBI
among the male study participants was $70.43 \pm 11.32$ and the mean PGWBI among female was $60.26 \pm$
15.08. The mean PGWBI among male participants was more than that of the female participants and the
difference was statistically significant (P value < 0.05$)$. There was statistically significant different in
mean PGWBI values among various duration of illness categories (P value $<0.05)$. The highest was in
the more than 20 years category (76.50 \pm 8.10$)$ followed by less than or equal to 5 years category (72.11
$\pm 11.34)$.
Conclusion: Spouses in this study experienced significant burden and distress both subjectively and
objectively. Female spouses experience significant caregiver burden compared to their male spouses.
Keywords: Bipolar disorder, spouses, psychological wellbeing.

\section{Introduction}

Bipolar Affective Disorder (BPAD) is a chronic mental disorder characterized by acute episodes of mania, hypomania, and major depression. ${ }^{1}$ According to American Psychiatric Association (APA, 2013) Diagnostic and Statistical Manual of Mental Disorders (DSM-V), Bipolar disorder is classified into four main subtypes: Bipolar I disorder (BDI), bipolar II disorder (BDII), cyclothymia and BD not otherwise specified. ${ }^{2}$ Bipolar disorder affects around $2.4 \%$ of the global population. ${ }^{3}$ In 2017, 7.6 million people had bipolar disorder in India. Mental disorders were the leading cause of YLDs in India, contributing $14.5 \%$ of the total YLDs in $2017 .{ }^{4}$

Caregivers play a major role in the management of all the chronic mental illnesses. Care giving is a time-consuming responsibility, creatingsocial, emotional, financial and behavioral problems for the caregivers and causes various limitations on their personal life. World Health Organization (WHO) states care giver burden as "The 
emotional, physical, financial demands and responsibilities of an individual's illness that are placed on the family members, friends or other individuals involved with the individual outside the health care system."

Families in India were largely inter-dependent and there is a concern regarding one's well-being for every member of the family. Hence there used to be a high involvement of family members in treating their mentally ill relatives. Caring for a mental disorder patient can affect the family dynamics. It takes up most of the caregiver's time and energy. In Indian context, for married mentally ill persons, their spouses used to be the primary caregiver if they continue to live together. For both mentally ill male and female patients, their spouses have to provide assistance with activities of daily living, management of disease and emotional support to the patient.

Caregivers experience poorer self-reported health, engage in less health promotion activities than non- caregivers, and report lower life satisfaction because of high caregiver burden and responsibilities. ${ }^{6}$ Family members living with a person with bipolar disorder reported poorer physical health, reduced activity, and greater health service utilization comparing to noncaregivers. $^{7}$

Patient's unmanageable and unpredictable behavioral problems leads to stress and anxiety in caregivers which may further leads to depression, stress, and physical ill health. ${ }^{8}$ Sudden changes in mood and behavior adversely affect various aspects of the lives of both patients and caregivers including employment, financial functioning, physical and mental functioning and social interactions. ${ }^{9-11}$ Patient's symptoms and increased hours of contact with the patient were related to higher levels of distress. Care giving has a negative impact on quality of life, and is associated with other adverse effects, including poorer self-rated health, chronic medical conditions, increased health care utilization.

Psychological wellbeing is a health related quality of life measure that is a subjective, psychological dimension. The resulting components that are generally measured by health related quality of life scales are general health, emotional health, vegetative symptoms, autonomy, accomplishment and understanding.

Psychosocial functioning consists of various behavioural domains such as the individuals' capacity to function socially or occupationally, to live independently, and to engage in a romantic life, with functional recovery typically being defined as the restoration of normal role functioning in the domains under scrutiny. ${ }^{12,13}$

\section{Methodology \\ Materials \& Methods \\ Source of data}

A cross sectional study was done during the period of August 2021- November 2021, in the Psychiatry Department of Rajah Muthiah Medical College Hospital, Chidambaram. It is a tertiary care hospital. For this study, a sample size consisting of 40 spouses of bipolar patients were included in the study.

\section{Inclusion criteria for patients}

Diagnosed as Bipolar affective disorder according to ICD-10

\section{Exclusion criteria for patients}

- Comorbid physical and other Psychiatric illness

- Organic illness

- Associated with personality disorder or MR

\section{Inclusion criteria for caregivers:}

- Spouses of the index patient who actively involved in the care of the patient and living with the patient

\section{Exclusion criteria for Caregivers}

- Co-morbid physical and other psychiatric illness

- Associated with personality disorder or MR

\section{Sampling Methods}

Patients with a diagnosis of bipolar affective disorder and their spouses attending the Psychiatric outpatient department in Rajah Muthiah Medical College hospital, were included 
in the study, after getting the informed consent about the study were included.

\section{Assessment of the study population}

Spouses were administered socio-demographic data sheet and Psychological General Well Being Index. ${ }^{14}$

\section{Psychological General Well-Being Index}

This scale was mainly developed for the evaluation of perceived well-being and distress. It consists of 22 items which described under six dimensions: 1.Anxiety, 2.Depression, 3. Positive Well-Being, 4.Self-Control, 5. General Health, and 6.Vitality.

The original scoring by item was $0-5$, giving a maximal score of 110.In several studies, the scoring has been changed to 1-6, giving a score range of 22-132. Although it is primarily selfadministered it has also been administered by an interviewer or completed by relatives. Measurements of well-being have also been made on normal populations and during health examination programmes. It is a general measure of subjective well-being and hence not condition specific.

\section{Results}

Among the participants, $32.5 \%$ were in the age group 31 to 40 years and 41 to 50 years, respectively. $47.5 \%$ of the participants were males and $52.5 \%$ of the participants were females. Among the males, $36.8 \%$ were in the age group 31 to 40 years and $31.6 \%$ were in the age group 41 to 50 years. Among the females, $33.3 \%$ were in the age group 41 to 50 years and $28.6 \%$ were in the age group 31 to 40 years and 51 to 60 years, respectively. Among the participants, $22.5 \%$ were married for 11 to 15 years and > 25 years, respectively and $17.5 \%$ were married between 6 and 10 years. $27.5 \%$ participants had studied up to high school followed by $22.5 \%$ up to middle school. $32.5 \%$ were unemployed followed by $15 \%$ were doing unskilled job and self-employed, respectively. $27.5 \%$ belonged to lower middle class and $22.5 \%$ belonged to upper middle class. Among the study participants, $72.5 \%$ resided in rural areas, $87.5 \%$ were Hindus and $75 \%$ lived in nuclear family. $77.5 \%$ had illness above 5 years and $55 \%$ were not complying with treatment regularly.

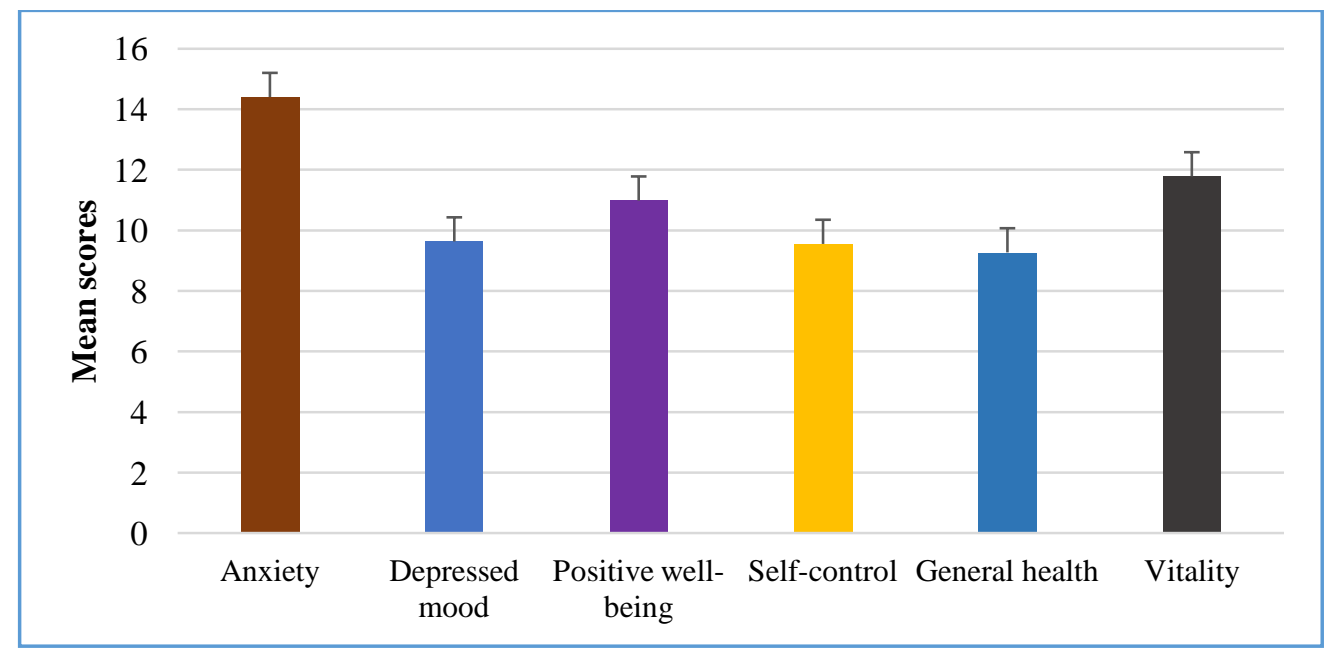

Fig 1: Bar chart showing mean of categories under psychological general wellbeing index

$\checkmark$ The mean score for anxiety was $14.40 \pm$ 3.70 .

$\checkmark$ The mean score for depressed mood was $9.63 \pm 2.23$

$\checkmark$ The mean score for positive wellbeing was $10.98 \pm 2.94$ $\checkmark$ The mean score for self-control was $9.55 \pm$ 1.86

$\checkmark$ The mean score for general health was $9.27 \pm 2.44$

$\checkmark$ The mean score for vitality was $11.78 \pm$ 2.64

$\checkmark$ The mean total score was $65.60 \pm 14.04$ 


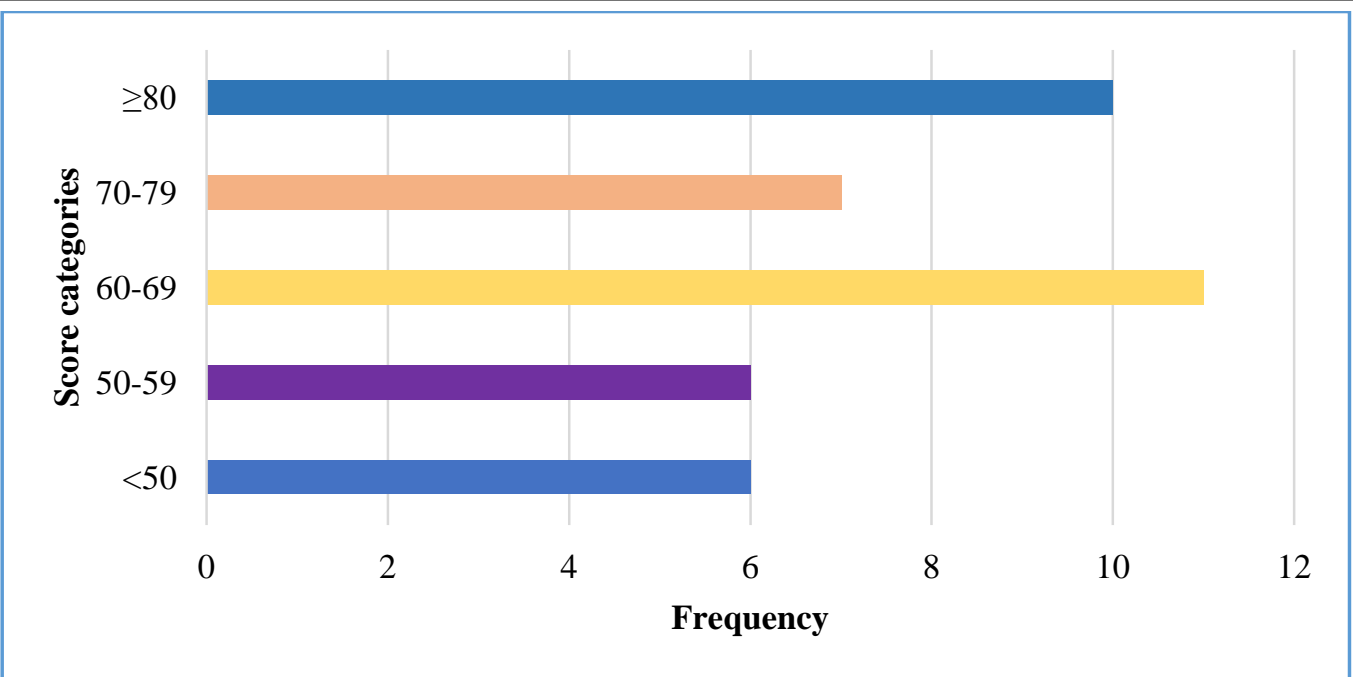

Fig 2: Bar chart showing distribution of total score of psychological general wellbeing index

$27.5 \%$ had psychological general wellbeing index of 60 to 69 and about $25 \%$ had psychological general wellbeing index of more than or equal to 80.

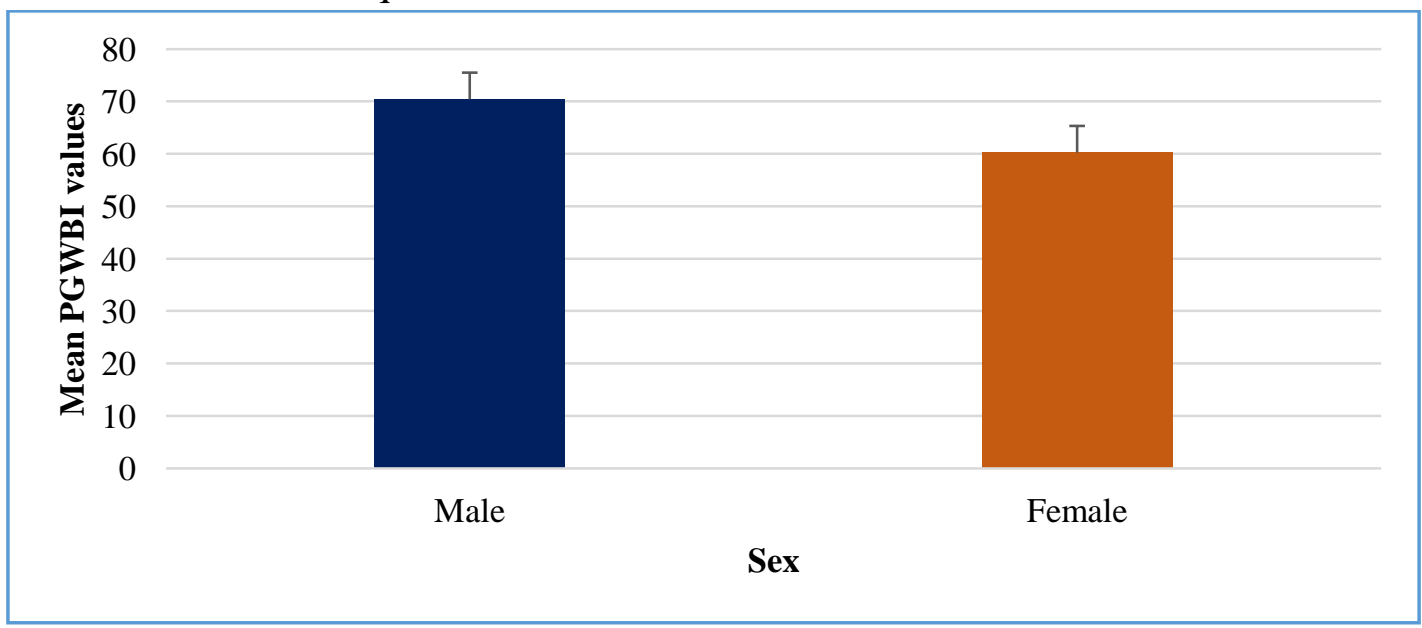

Fig 3: Bar chart showing comparison of mean PGWBI among various sex among study participants

The mean PGWBI among the male study participants was $70.43 \pm 11.32$ and the mean PGWBI among female was $60.26 \pm 15.08$. The mean PGWBI among male participants was more than that of the female participants and the difference was statistically significant $(\mathrm{P}$ value < $0.05)$.

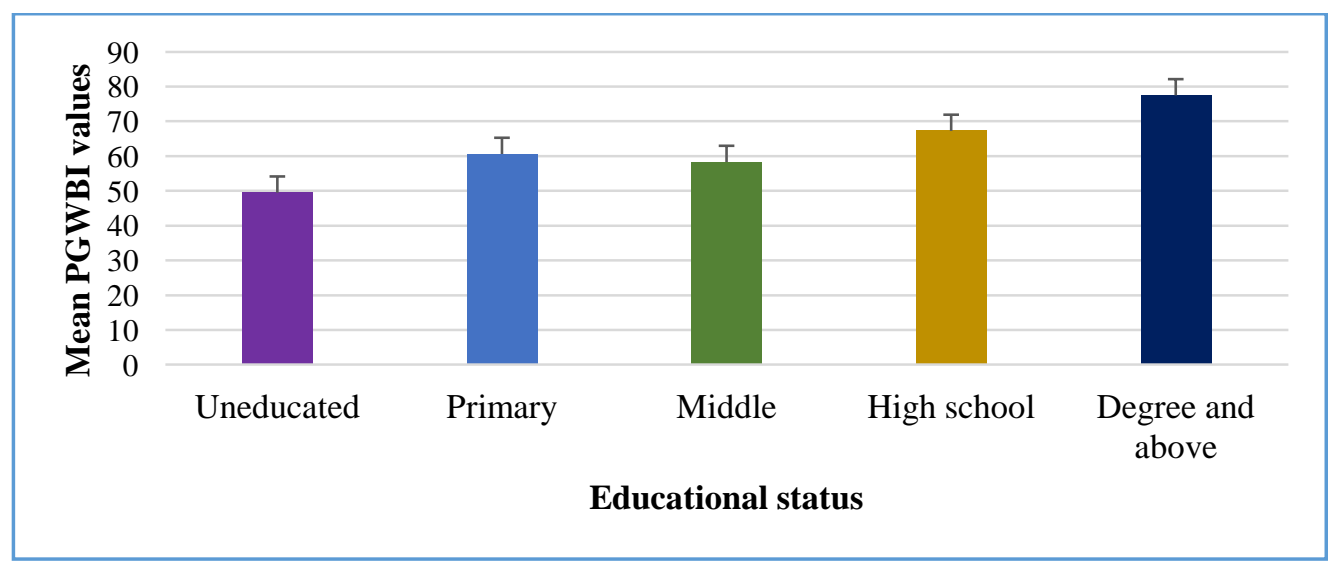

Fig 4: Bar chart showing mean PGWBI among various educational categories of the study participants 


\section{JMSCR Vol||09||Issue||12||Page 31-37||December}

The mean PGWBI among the participants who were uneducated was $49.50 \pm 4.95$, among those educated up to primary school was $60.63 \pm 11.10$, among those who had studied up to middle school was $58.33 \pm 15.00$, among those studied up to high school was $67.27 \pm 11.75$ and those who had studied up to degree and above was $77.50 \pm 10.43$. All the categories' mean PGWBI was found to be statistically distinct with $\mathrm{P}$ value of less than 0.05 .

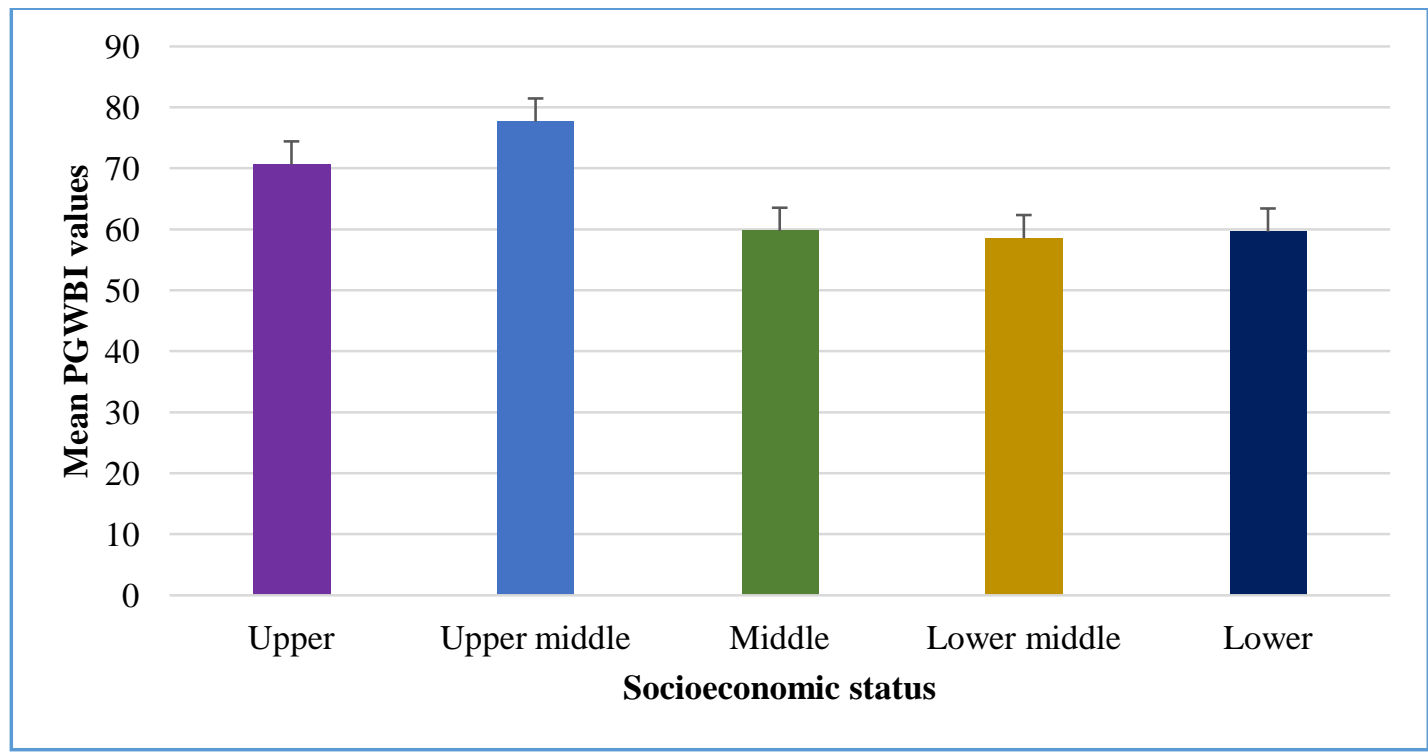

Fig 5: Bar chart showing mean PGWBI among various socioeconomic status categories

Among the participants with upper socioeconomic status, the mean PGWBI was $70.63 \pm 11.74$, among those with upper middle class it was 77.67 \pm 10.93 , among those with middle it was $59.75 \pm$ 7.54 , among those with lower middle class it was
$58.55 \pm 13.80$ and among those in lower class, the mean was $59.63 \pm 13.14$. There was statistically significant difference in mean PGWBI between various socioeconomic categories. The mean was highest among the upper classes.

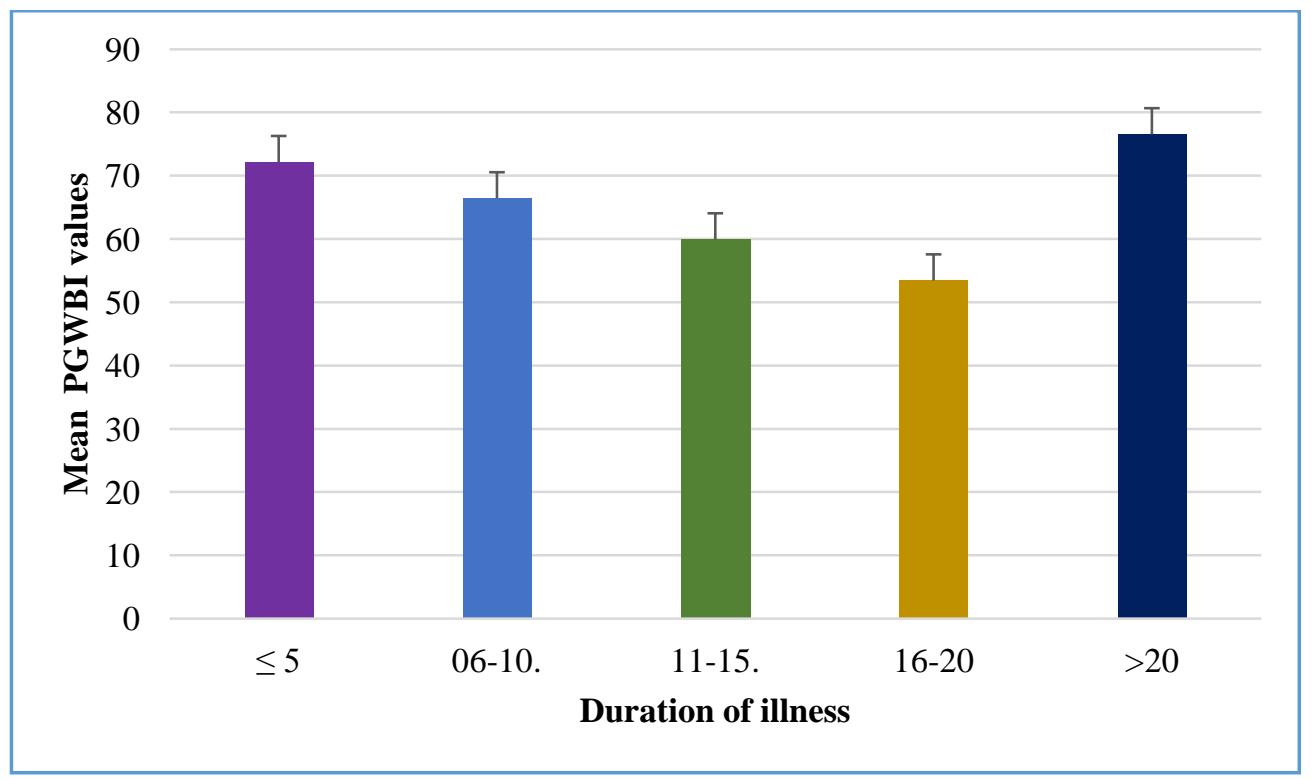

Fig 6: Bar chart showing mean PGWBI among various duration of illness categories

Among the patients with duration of illness of less than or equal to 5 , the mean PGWBI was $72.11 \pm$
11.34, among those with duration between 6 to 10 , the mean was $66.38 \pm 16.31$, among those with 
duration between 11 and 15 , the mean was 59.89 \pm 11.19 , among those with the duration of 16 to 20 years the mean was $53.40 \pm 9.55$ and among those with duration more than 20 years it was $76.50 \pm$ 8.10. There was statistically significant different in mean PGWBI values among various duration of illness categories ( $\mathrm{P}$ value $<0.05)$. The highest was in the more than 20 years category followed by less than or equal to 5 years category.

\section{Discussion}

This study was carried out on 40 spouses of persons diagnosed with Bipolar Affective Disorder attending the Psychiatry outpatient department at Rajah Muthiah Medical College Hospital, Chidambaram. This study was conducted in the spouses of Bipolar Affective Disorder patients to assess their psychological well-being.

\section{Socio- demographic profile of the patient}

The patients mainly belong to middle age group (37.5\% in age group 31 to 40 years and $22.5 \%$ in age group 41 to 50 years) with slight female preponderance $(52.5 \%)$. Majority of patients belong to rural background $(72.5 \%)$ following Hinduism (87.5\%) and are living in nuclear family arrangement (75\%). 55\% of the patients had less than 10 years of illness and $45 \%$ of patients were regularly compliant to treatment.

\section{Socio-demographic profile of the spouses}

Majority of spouses, the study population belong to middle age group (65\% in the age group 31-50 years) with slight male preponderance $(52.5 \%)$. Most of the couples are in marital relationship for over 10 years $(70 \%) .25 \%$ of the study population were graduates, $27.5 \%$ finished school education, $25 \%$ were either illiterates or had primary education. Majority of spouses were either unemployed or homemakers. The study population is distributed among various socioeconomic gradients, family arrangements and location of residences.

\section{Psychological well-being}

Psychological well-being is inversely proportionate to caregiver burden. Male spouses have significantly higher scores in psychological well-being comparing to female spouses indicating that females have to undergo more stress and burden leading to low PGWBI scores because of their male partners' illness.

Regarding educational qualification of the spouses, educated people especially graduates have higher scores of PGWBI, while illiterates have lower scores indicating the role of awareness and knowledge about the illness among the educated spouses made them cope well with the situation.

Regarding socio-economic status, upper and upper middle class people have higher scores in PGWBI, showing that better socio-economic status can have better psychological well-being. But from this study, there was no significant difference considering family arrangement or location of residence.

Considering the duration of the illness, longer the duration of illness, lower the PGWBI values until 20 years of illness. This indicates the duration of illness has a negative effect on psychological well-being of spouses. But for spouses experiencing burden over 20 years, higher PGWBI scores are noted probably due to reduced severity of illness.

\section{Conclusion}

This cross-sectional study is done to assess the caregiver burden and psychological well-being experienced by the spouses of bipolar affective disorder patients and Psychological Well Being Index scale was administered.

Majority of the patients and spouses belong to middle age group with $55 \%$ of the patients have illness less than 10 years. The study sample comprised of population belonging to varying educational qualification, occupations and socioeconomic background. Most couples are coming from rural background and living in a nuclear family arrangement.

Lower PGWBI scores indicate that the female spouses and those with caregiver role for a long period of time are experiencing greater burden. 
However, higher PGWBI scores were observed in educated spouses and with better socio-economic status which might be due to better coping skills, awareness about the illness and better economic status.

The main inference of our study was significant demands are being placed on the spouses of BPAD patients who in turn affect their physical and mental health, but still researches targeting this aspect were few. Future studies has to be focused on the various aspects of caregivers burden as they play an important role in the prognosis and outcome of chronic mentally ill patients like BPAD by focusing not only in the symptom recovery but also return to normal functioning and attainment of a meaningful life.

\section{References}

1. Anderson, I.M., Haddad, P.M., Scott, J., 2012. Bipolar disorder. BMJ: British Medical Journal345, e8508.

2. American Psychiatric Association, 2013. Diagnostic and Statistical Manual of Mental Disorders: Fifth Edition. http://dsm.psychiatryonline.org/doi/book/ 10.1176/appi.books. 9780890425596

3. Merikangas KR, Jin R, He JP, Kessler RC, Lee S, Sampson NAet al (2011) Prevalence and correlates of bipolar spectrum disorder in the world mental health survey initiative. Arch Gen Psychiatry 68(3):241-251

4. India State-Level Disease Burden Initiative Mental Disorders Collaborators. The burden of mental disorders across the states of India: the Global Burden of Disease Study 1990-2017. Lancet Psychiatry. 2020 Feb;7(2):148-161. doi: 10.1016/S2215-0366(19)30475-4. Epub 2019 Dec 23. PMID: 31879245; PMCID: PMC7029418.

5. A glossary of terms for Community health care and services: WHO Centre forhealth development: WHO:2005; 5.
6. Amirkhanyan, A.A.,\& wolf, D.A.caregiver stress and non-caregiver stress; Exploring the pathways of psychiatric morbidity.Gerontologist.2003;43,817-827.

7. Ghannam, B.M., Hamdan-mansour, A.M., Al Abeiat, D.D., 2016. Burden among caregiverpsychological correlates of burden among Jordanian. Perspect. Psychiatric Care 1-8. https://doi.org/10.1111/ppc.12179.

8. Williamson, G.M.,\& Schulz, R. Coping with specific stressors in Alzheimer's Disease care giving. The Geronotologist. 1993;33, 747-755.

9. Hawke, L.D., Parikh, S.V., Michalak, E.E., 2013. Stigma and bipolar disorder: a review of the literature. J. Affect. Disord. 150, 181-191.

10. IsHak, W.W., Brown, K., Aye, S.S., Kahloon, M., Mobaraki, S., Hanna, R., 2012. Health-relatedquality of life in bipolar disorder. Bipolar disorders 14, 618.

11. Michalak, E.E., Yatham, L.N., Maxwell, V., Hale, S., Lam, R.W., 2007. The impact of bipolardisorder upon work functioning: a qualitative analysis. Bipolar disorders 9,126-143.

12. Bonnín CD, Reinares M, Martínez-Arán A, Jiménez E, Sánchez-Moreno J, Solé B, Montejo L, Vieta E. Improving functioning, quality of life, and well-being in patients with bipolar disorder. International Journal of Neuropsychopharmacology. 2019 Aug; 22(8):467-77.

13. Zarate CA Jr, Tohen M, Land M, Cavanagh S (2000) Functional impairment and cognition in bipolar disorder. Psychiatr Q71:309-329.

14. Gisella Rose (1996) .Effects of a health examination programme on qualityof life and subjective well-being Scand J Public Health June 1996 vol. 24no.2 124-131. 